\title{
Viral misdirection
}

\author{
While the pandemic creates a 'new normal', many political, environmental and economic dynamics that were \\ concerning us before 2020 have become all the more serious under the cover of COVID-19's long shadow.
}

T

he 'Chinese curse', "May you live in interesting times", might have little connection with China, but its implication that 'interesting' times are neither peaceful nor pleasant has never been truer. The COVID-19 pandemic has driven almost everything else from the news pages, the problems that concerned us 12 short months ago have not disappeared, and many have been exacerbated.

Concurrent with the health costs being suffered from COVID-19 is the economic millstone of lockdowns being endured by millions. In $\mathrm{May}^{1}$, we wrote of how supply and demand for food had been affected by the pandemic. Recent months have seen some stabilization in production and supply chains, but the situation remains fragile. New efforts and research on sustainable solutions for zero hunger like the Ceres2030 programme (featured in Nature Plants and our sister journals ${ }^{2}$ ) are thus all the more important. Food insecurity may double across the world's population this year, and even in the richest country on Earth, the USA, eight million people have fallen into poverty since the onset of the pandemic ${ }^{3}$, disproportionately minorities and children.

This follows controversial changes to America's food assistance, which were already taking place in 2018 (ref. $\left.{ }^{4}\right)$. At that time, the US Department of Agriculture (USDA) was getting ready to shift at least partially from so-called 'food stamps', that can be exchanged at grocery stores, to boxes of pre-selected foods. The USDA has sent 100 million boxes since May this year, alleviating some of the strain on food banks nationwide, but a federal court had to stop the department from stripping assistance from 700,000 qualified Americans ${ }^{5}$. Meanwhile, the USDA was fending off accusations of partisan influence when it started inserting letters in the boxes signed by President Trump who, in the letter, claimed credit for sending them ${ }^{6}$. Some food banks, which receive the boxes from the government to distribute to local recipients, were placed in the position of either refusing to hand them out or having to remove the letter, box by box, to avoid breaking rules regarding political activity.

During this pandemic, urban residents worldwide have been ordered to lock down for weeks, sometimes multiple times, with limited time outdoors and even less green space in which to enjoy it. Conflicts over common spaces are unlikely to go away anytime soon, as we featured two years ago ${ }^{7}$, but evidence of disparate access to such valuable and shared landscapes is mounting. A recent Friends of the Earth study ${ }^{8}$ in the United Kingdom found that minorities were twice as likely to live in areas deprived of green spaces as their white counterparts. We ourselves saw that early in lockdown, parks in predominantly rich and white west London remained open, while Victoria Park, the largest such space in east London (an area with a higher youth and ethnic population), was closed for ten days. Social distancing regulations are important, but the mental and physical health benefits of being in the outdoors are not trivial. Hopefully the 'new normal' following the pandemic will see renewed focus on combatting these inequalities of access to green food and green space.

In 2018, we noted that a lawsuit awarding $\$ 289$ million to a groundskeeper, who argued that his non-Hodgkin lymphoma resulted from constant exposure to glyphosate in the herbicide Roundup, was only the tip of the iceberg 9 . Some 120,000 lawsuits were aimed at the global agribusiness giant Bayer, who inherited the potential liability when it bought Monsanto for $\$ 63$ billion. This past July, the company announced a $\$ 10$ billion settlement for 95,000 of those claims ${ }^{10}$. Some of the money will be put towards an independent commission to determine whether glyphosate is a carcinogen or not. But while the academic research is ongoing, the sheer size of the settlement may well crystallize public opinion.

Even COVID-19 can't hide the continued escalation of wildfires around the world. We previously wrote about the 'unnatural disaster' of fires; simultaneously fuelled by and disrupting human society ${ }^{11}$. Australia's inferno, named the 'Black Summer' by locals, began in 2020, with reports of a billion animals and birds lost within 18.6 million scorched hectares. Some species will have gone extinct and 306 million tons of $\mathrm{CO}_{2}$ have been emitted ${ }^{12}$.
This year has also brought the worst fire season ever to the west coast of the USA, bathing San Francisco in an orange haze. During the Australian fires, The Guardian declared this the age of 'megafires'"3; by October, when several fires in Northern California merged into a single conflagration spanning over 400,000 hectares, this was upgraded to 'gigafires ${ }^{14}$. Almost lost under the metaphorical smoke from those disasters was another record-breaking fire season in the Amazon rainforest. Less than a year after we wrote about fires that seized the attention of the world ${ }^{15}$, the number of hotspots and fires have been larger still. Meanwhile, the nearby Pantanal tropical wetland is suffering 'apocalyptic' impacts ${ }^{16}$, despite having an ecosystem adapted to fire.

It is easy to be overwhelmed by the news this year. But global challenges do not go away just because a more immediate threat enters the stage. To behave otherwise would be to allow COVID-19's indirect effects to be more devastating than the millions it will permanently incapacitate and kill.

Published online: 9 November 2020 https://doi.org/10.1038/s41477-020-00812-x

References

1. Nat. Plants 6, 429 (2020).

2. Sustainable solutions to end hunger. Nature https://gonature, com/3jytSAe (2020).

3. Sykes, S. 8 Million Americans Slipped Into Poverty Amid Coronavirus Pandemic, New Study Says. NBC News https://nbcnews.to/3dWHmEK (2020).

4. Nat. Plants 4, 189 (2018).

5. Hsu, S. S. Federal Judge Strikes Down Trump Plan to Slash Food Stamps for 700,000 Unemployed Americans. The Washington Post https://wapo.st/3kJbcPX (2020).

6. Bottemiller Evich, H. Trump Requires Food Aid Boxes to Come with a Letter from Him. Politico https://politi.co/31KRtHT (2020).

7. Nat. Plants 3, 755 (2017)

8. de Zylva, P., Gordon-Smith, C. \& Childs, M. England's Green Space Gap (Friends of the Earth, 2020); https://bit.ly/3ovFkAj 9. Nat. Plants 4, 617 (2018).

10. Cohen, P. Roundup Maker to Pay $\$ 10$ Billion to Settle Cancer Suits. The New York Times https://nyti.ms/3e0t4mt (2020). 11. Nat. Plants 3, 17124 (2017).

12. Lee, H. Bushfires Release Over Half Australia's Annual Carbon Emissions. Bloomberg Green https://bloom.bg/3jvNDIX (2019). 13. Flannery, T. This is the Age of the Megafire - and it's Being Fuelled by our Leaders. The Guardian https://bit.ly/2Ttnqjz (2020).

14. Milman, O. \& Ho, V. California Wildfires Spawn First 'Gigafire' in Modern History. The Guardian https://bit.ly/3kBRYM4 (2020). 15. Nat. Plants 5, 1025 (2019).

16. Rodríguez Mega, E. 'Apocalyptic' Fires are Ravaging the World's Largest Tropical Wetland. Nature https://go.nature. $\mathrm{com} / 3 \mathrm{dWWAOM}(2020)$. 